\title{
Intracranial Ricocheting of Bullet from Anterior Clinoid Process
}

\author{
Agrawal A, ${ }^{1}$ Pratap A, ${ }^{2}$ Rauniar RK, ${ }^{3}$ Kumar A, ${ }^{2}$ Nepal U ${ }^{2}$ \\ 'Department of Surgery, ${ }^{2}$ Department of Surgery, ${ }^{3}$ Department of Radiology, BPKIHS, Dharan, Nepal
}

\begin{abstract}
Gunshot wounds to the head are usually mortal injuries. We present a unique case of intracranial ricocheting of bullet without neurological deficits. Patient was treated conservatively with antibiotics for one week and prophylactic anticonvulsants for six weeks. Patient is doing well at six months follow up. Repeat X-ray skull showed that bullet was lying in the occipital region. It is recommended that deep seated bullets should be left behind as any attempt to remove that bullet may increase the morbidity and mortality. However close follow up of these patients is very important as these patients may come back with brain abscess.
\end{abstract}

Key words: bullet, gunshot wounds, firearm

\section{INTRODUCTION}

Gunshot wounds to the head are usually mortal injuries. ${ }^{1-3}$ Their frequency has been increasing in the last years because of increasing crime, armed struggle between political parties and war rates. ${ }^{1}$ We present a unique case of intracranial ricocheting of bullet without neurological deficits and discuss the mechanism behind the spontaneous migration of the bullet in the brain tissue. There are only few literature reports of spontaneous migration of a bullet within the brain. ${ }^{4,5}$ This case is unique presentation as the patient was without any neurological deficit. ${ }^{5}$

\section{CASE REPORT}

Twenty-seven years female presented six hours after gunshot injury to the head with headache and multiple episodes of vomiting. There was history of transient loss of unconsciousness. Her general and systemic examination was normal. On neurological examination there were no focal deficits. Local examination revealed an entry wound on the right side of forehead with bleeding that was sutured. Computerized scan CT scan showed small depressed fracture of the right frontal bone and indriven bone fragments with underlying frontal haematoma. Bullet was seen in the deep right parietal lobe. There was also the haematoma along the trajectory (tract haematoma) of the bullet (Figure1). She was treated conservatively with antibiotics (Injection Ceftriaxone, Gentamicin and Metronidazole for one week), prophylactic anticonvulsants (Phenytoin for six weeks) and recovered without deficits. Repeat $\mathrm{X}$-ray skull at six months showed that bullet was lying in the occipital region (Figure-2). Patient was doing well at one year follow up.

\author{
Correspondence: \\ Dr. Amit Agrawal \\ Department of Surgery \\ BPKIHS, Dharan, Nepal. \\ Phone: +977-25-525555 ext 2047 \\ Email: dramitagrawal@gmail.com
}




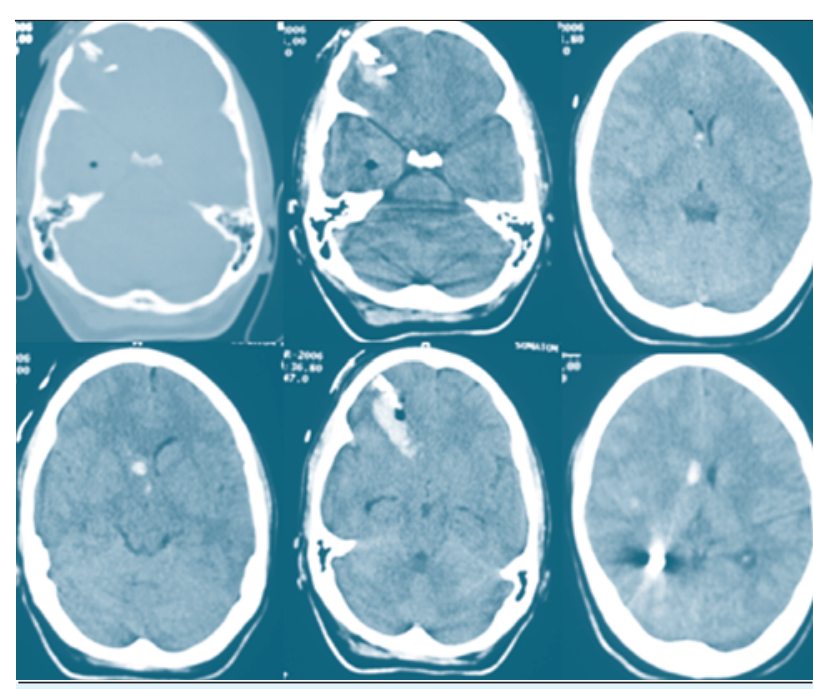

Figure-1. CT scan serial sections showing the trajectory of the bullet and associated lesions along the trajectory

\section{DISCUSSION}

It is a unique case of intracranial ricocheting of bullet without neurological deficits. There is no consensus about the surgical indications or aggressiveness because of the great number of variables to be considered, such as the number and distribution of fragments,

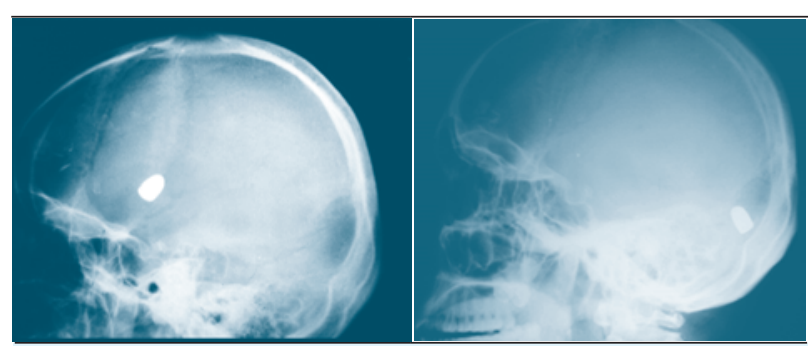

Figure-2a. X-ray skull lateral view showing the location of bullet (left-at day 1)Figure-2b. X-ray at 6 months follow up

the occurrence of different types of lesions caused by different types of missiles and shrapnel particles, and the involvement of eloquent areas. ${ }^{2}$ As the patient did not have deficits and deep location of the bullet, the patient was treated conservatively. While treating the patient conservatively, the resting position should be dictated in order to avoid an eventual migrating bullet to eloquent regions of the brain causing additional neurological deficits. ${ }^{3,5}$ As we presume in the present case the spontaneous migration of intracerebral bullets is influenced by cerebral softening, the specific gravity of the bullet compared with brain tissue, and the sink function of the cerebral ventricles. ${ }^{5}$

\section{REFERENCES}

1. Karabagli H. Spontaneous movement of bullets in the interhemispheric region. Pediatr Neurosurg 2005;41(3):14850 .

2. Bakir A, Temiz C, Umur S, Aydin V, Torun F. High-velocity gunshot wounds to the head: analysis of 135 patients. Neurol Med Chir (Tokyo) 2005;45(6):281-7.

3. Liebeskind AL, Anderson RD, Schechter MM. Spontaneous

movement of an intracranial missile. Neuroradiology 1973;5(3):129-32.

4. Ozkan U, Ozateş M, Kemaloğlu S, Güzel A. Spontaneous migration of a bullet into the brain. Clin Neurol Neurosurg. 2006;108(6):573-5.

5. Milhorat TH, Elowitz EH, Johnson RW, Miller JI. Spontaneous movement of bullets in the brain. Neurosurgery. 1993;32(1):140-3. 